\title{
Simulating schizophrenia
}

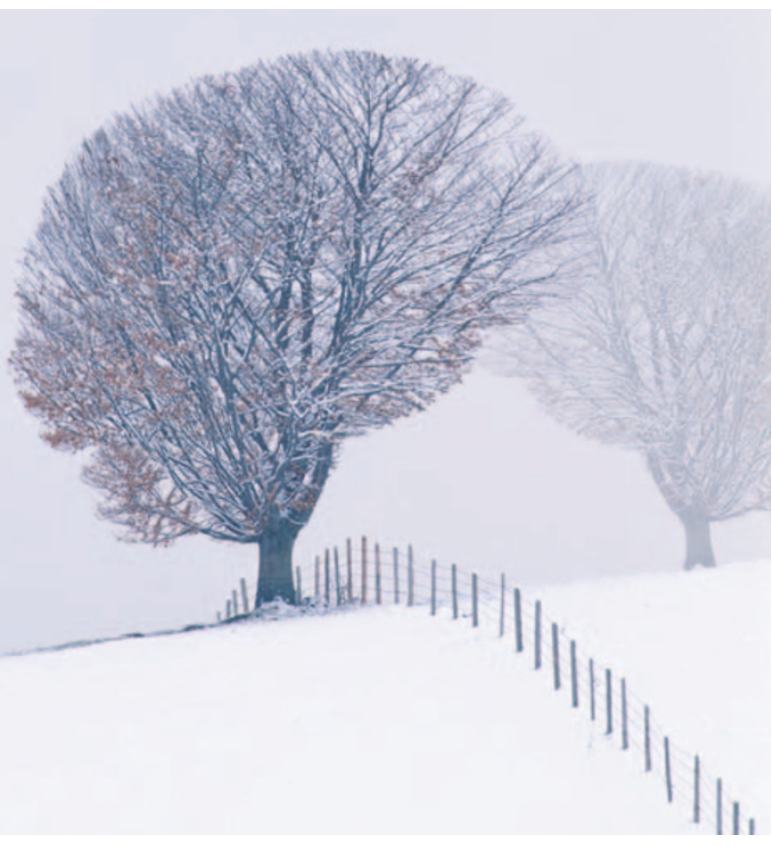

Modelling human psychiatric disorders in animals is challenging, in part because the mechanisms that underlie such disorders are complex, and often interrelated. This makes the generation of animal models that reproduce all the characteristics of a particular disease difficult, if not impossible. Nevertheless, Kellendonk and colleagues from the Kandel group, writing in Neuron, now describe an elegant new mouse model of schizophrenia that sheds light on the pathophysiology of this disorder and could aid in the development of new drugs.
Overactivity of dopamine $2\left(\mathrm{D}_{2}\right)$ receptors has long been implicated in the pathophysiology of schizophrenia. Indeed, all effective antipsychotic drugs block $\mathrm{D}_{2}$ receptors and, in particular, improve the positive symptoms of the disease, such as hallucinations and delusions. However, these drugs typically only have modest beneficial effects on cognitive impairments associated with schizophrenia, such as deficits in working memory, and it has been more difficult to determine whether $\mathrm{D}_{2}$ receptors have any role in these symptoms.

To investigate this issue, Kellendonk and co-workers developed transgenic mice in which overexpression of $\mathrm{D}_{2}$ receptors was restricted to the striatum, as increased activity of $\mathrm{D}_{2}$ receptors in this area has been implicated in schizophrenia. Importantly, expression of the $\mathrm{D}_{2}$ receptor transgene could be 'switched off' by oral administration of the antibiotic doxycycline.

Although the general behaviour of the mice overexpressing $\mathrm{D}_{2}$ receptors was unaffected, standard tests of working memory and behavioural flexibility showed that the mice had cognitive impairments similar to those experienced by people with schizophrenia. The deficits in working memory remained after administration of doxycycline to the mice, suggesting that it is excess $D_{2}$ receptor activity during development, rather than continued overexpression, that is important in causing these deficits. The authors also note that this might explain why treatment with current anti-psychotic drugs does not significantly affect cognitive deficits in schizophrenic patients: such treatment is too late to reverse the underlying physiological alterations.

Finally, Kellendonk et al. investigated the effects of striatal overexpression of $\mathrm{D}_{2}$ receptors in the prefrontal cortex (PFC), the main structure associated with working memory, and noted changes in dopamine levels, rates of dopamine turnover and activation of $\mathrm{D}_{1}$ receptors in the $\mathrm{PFC}$, all of which are crucial in working memory. The authors therefore suggest that it will be interesting to assess whether $D_{1}$ receptor blockade in the PFC would reverse the cognitive deficits in their $\mathrm{D}_{2}$ transgenic mice, potentially highlighting an avenue for the development of improved antipsychotic drugs. And in general, this model could prove useful in predicting the effects of any potential antipsychotic agent on the cognitive impairments associated with schizophrenia in humans.

\section{Samantha Barton}

ORIGINAL RESEARCH PAPER Kellendonk, C. et al. Transient and selective overexpression of dopamine D2 receptors in the striatum causes persistent abnormalities in prefrontal cortex functioning. Neuron 49, 603-615 (2006)

\section{RESEARCH HIGHLIGHTS ADVISORS}

ERIK DE CLERCQ

Katholieke Universiteit Leuven, Belgium RODERICK FLOWER

William Harvey Research Institute, QMW, London, UK

YOSHIJI FUIITA

Clinical Proteome Center, Tokyo Medical

University
F. PETER GUENGERICH

Vanderbilt University Nashville, TN, USA FRANZ HEFTI

Rinat Neuroscience Corporation, Palo Alto, CA, USA

JOAN HELLER BROWN

University of California San Diego,

CA, USA
MADS KROGSGAARD THOMSEN

Novo Nordisk, Bagsvaerd, Denmark HUGO KUBINYI

University of Heidelberg, Germany ROBERT LANGER Massachusetts Institute of Technology Cambridge, MA, USA JULIO LICINIO University of California Los Angeles, CA, USA
CHRISTOPHER LIPINSKI

Pfizer Global Research and Development, Groton, CT, USA TOMI SAWYER

Ariad Pharmaceuticals, Cambridge, MA, USA JANET WOODCOCK

JANET WOODCOCK
Food \& Drug Administration, Rockville, MD, USA 